\title{
How to measure professional discrimination in healthcare settings?
}

\section{Azita Jaberi}

Shiraz University of Medical Sciences

\section{Fatemeh ZareKhafri}

Shiraz University of Medical Sciences

Camellia Torabizadeh ( $\nabla$ torabik@sums.ac.ir)

https://orcid.org/0000-0003-2193-5844

\section{Research}

Keywords: Discrimination, Validity, Reliability, Healthcare policy

Posted Date: January 20th, 2020

DOI: https://doi.org/10.21203/rs.2.21347/v1

License: (c) (i) This work is licensed under a Creative Commons Attribution 4.0 International License. Read Full License 


\section{Abstract}

Professional discrimination is one of the most important challenges of inter-professional interaction. To understand and describe this concept from the viewpoints of health team members, a scientific tool is required to measure professional discrimination based on which planning and decision-making will be possible. Materials and

Methods: The present methodological study was conducted in qualitative and quantitative phases. In the first phase, the main aspects of the concept of professional discrimination were defined through extensive literature review and viewpoints of experts and nurses. In the quantitative phase, after designing and extracting the tool items, validity (face, content, and construct) and reliability (internal consistency and stability) of the tool were assessed.

Results : Professional discrimination included some concepts, such as discrimination in employment promotion and access to educational opportunities, disparities in welfare compared to other careers such as physicians, disparities in superiors' behaviors towards inferiors like nurses in different situations, gender and ethnic discrimination, and the consequences of discrimination. In exploratory factor analysis, scree plot and factor load less than 0.4 showed that the questionnaire included five factors, namely "horizontal and vertical discrimination", "discrimination consequences", "inequality due to differences in employment, education, and ethnicity", and "ethnic and gender discrimination".

Conclusion: The results showed that the 33-item questionnaire had appropriate validity and reliability. Indeed, an overview of the existing tools showed that the questionnaire represented better than similar ones both in terms of the specificity of measuring the concept and evaluation of psychometric properties. Measurement of professional discrimination could provide health managers and decision-makers with highly accurate and documented information.

\section{Background}

All organizations need many resources to achieve their goals. Undoubtedly, the most important resource of any organization is its human resources, which would contribute to the success and progress of that organization if sufficiently motivated and satisfied (1).

Discrimination is one of the issues that could affect the motivation and satisfaction of health team members and various healthcare professionals, including nurses (2). By definition, discrimination is the denial of equal opportunities to enjoy social benefits, including education, employment, promotion, and access to housing and health care (3). In sociology, discrimination refers to a situation in which individuals with equal roles do not enjoy the social benefits of equality (4). Discrimination could cause undesirable consequences, such as psychological stress, fatigue, and repression, consequently impeding the achievement of organizational goals $(5,6)$. Various studies have shown that discrimination and injustice make people emotionally prone to conduct malicious behaviors, cause failure to perform tasks, lead to anger, decrease the quality and quantity of work, reduce commitment, and result in leaving the job 
(7-9). These behaviors affect the employees' commitment to the organization as well as their efficiency. Numerous studies have also shown a correlation between physical and psychological health dimensions and discrimination (10-13).

Feeling of inequality in the organization could occur in any profession. Current studies have revealed that one of the causes of injustice or discrimination in the workplace is sexual, cultural, or occupational discrimination $(7,14)$. Comparing nursing to other disciplines, especially medical disciplines, there are significant manifestations of discrimination. Differences in the quality of services, such as welfare and educational services, and respect in interactions are the most common forms of these discriminations $(15,16)$. Studies in Iran have also highlighted professional discrimination as one of the most important challenges of inter-professional interaction. For example, nurses have cited lack of equality in management authority and lack of professional value and respect as the most important forms of discrimination $(17,18)$.

Understanding and describing discrimination among health team members could provide valuable information to reduce and remove the existing problems and to plan for improving the quality of cares and services provided by them for the patients. To obtain such understanding, scientific and authenticity tools that can measure professional discrimination are required. However, to the best of our knowledge, there is no questionnaire specifically addressing professional discrimination. Although similar questionnaires, such as the Everyday Discrimination Scale (EDS) $(19,20)$, Major Experiences of Discrimination Scale (MED), Experience Discrimination Scale (EODS/EOD) (21), and Perceived Ethnic Discrimination Questionnaire-Community Version (PEDQ-CV) (long and short versions) (22), are available, many of these questionnaires refer to similar or partial concepts of professional discrimination. For example, they focus more on racial and ethnic discrimination than on professional discrimination. They usually contain questions about whether a person has been discriminated or unfairly treated in the school or workplace or in receiving social or medical services, which are non-specific questions about professional discrimination. Moreover, the organizational justice questionnaire, which has three components of distributive justice, procedural justice, and interactive justice, does not directly address the concept of discrimination (23-25).

All scholars in the questionnaire-making field believe that the content of questionnaires should be extracted directly from the people who the questionnaires refer to. This should be taken into account in defining the statements, wording, and literature. Therefore, the content of a questionnaire has to be consistent with the culture and way of life of the societies in which the tool is intended to be used (26) as well as with the theoretical structure underlying the tool (27). On the other hand, developing a questionnaire needs both qualitative and quantitative research designs (28).

A review of the literature indicated that among the available tools, an instrument for specific measurement of professional discrimination was not available and the existing tools did not go through all psychometric evaluation processes, such as face, content, and construct validity. Thus, the present study aims to design and validate an instrument for evaluation of professional discrimination. 


\section{Methods}

The present cross-sectional methodological study was conducted in two qualitative and quantitative phases. In the first phase of the research, the main aspects of the concept of professional discrimination were defined through extensive literature review and the viewpoints of experts and nurses. In the second phase, after designing and extracting the pool of items, the validity (face, content, and structure) and reliability (internal consistency and stability) of the questionnaire were assessed.

Phase I. Explaining the concept of professional discrimination

In this phase, articles were sampled and searched using search engines in electronic databases as well as manual searches in libraries, resources, and related research. To investigate published studies in Iran, Medlib, Iran Medex, Magiran, SID, and Irandoc databases were searched without time limit using the following keywords: discrimination, professional discrimination, justice, and instrumentation (scale or measure). The following sites were also searched for reviewing the studies performed in other countries: Google Scholar, CINAHL, PubMed, MEDLINE, ProQuest, Ovid, Elsevier, and Wiley. The inclusion criteria were relevance to the study and publication in English or Persian. Quantitative, qualitative, and review studies were included and keywords were searched for in the titles, keywords, or abstracts. Scientific articles had to be in the journals whose articles were peer-reviewed. Other formal studies were reviewed if they were published in books, including books on the concept of discrimination and professional discrimination. At the end of this phase, the concept of professional discrimination was defined, its dimensions and subscales were determined, and the pool of items was formed.

Phase II. Psychometric evaluation of the professional discrimination scale

- Determining the validity of the tool:

1- A) Face validity: Face validity was evaluated in both qualitative and quantitative terms. Considering the qualitative face validity of the questionnaire, to evaluate the rationality, appropriateness, attractiveness, and logical sequence of the items, face-to-face interviews were performed with the participants (19 nurses). After correction of the inappropriate items, in order to reduce and eliminate the inappropriate items and determine the importance of each item, quantitative face validity was assessed by calculating the Importance Score (IS). In doing so, 20 experts were asked to assign a score to each item using a fivepoint Likert scale ranging from 'very important' to 'not important at all'. Then, the IS for each item of the questionnaire was calculated as follows:

Importance $\times$ frequency $=$ Impact score

If this score was more than 1.5 , the subsequent analyses would be appropriate and the item would be maintained (29).

1-B) Content validity: Content validity was analyzed in both qualitative and quantitative ways. In doing so, 19 nursing instructors, nurses, and healthcare managers were asked to express their views on the 
appropriateness of the content of the tool in terms of "grammar compliance, use of appropriate words, placement of items in rightful place, and proper rating". Considering the quantitative content validity, 15 experts in nursing, psychiatry, and literature were asked to judge the content validity of the instrument based on Waltz and Bausell's (1983) Content Validity Ratio (CVR) and Content Validity Index (CVI). In this regard, they were requested to examine whether the presence of the items was necessary or not using a three-point spectrum (necessary, useful but not necessary, and not necessary). Then, the following formula was used to calculate the CVR for each item:

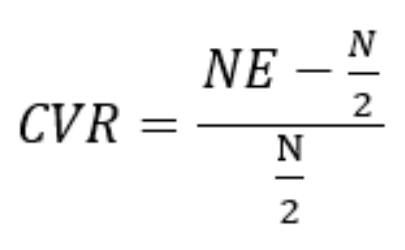

Afterwards, the results were compared to Lawshe table. If the calculated number was greater than the table number, the existence of the item was considered necessary (30).

To calculate the Item-Content Validity Index (I-CVI), the experts were asked to score each item based on the three criteria of "relevance", "clarity", and "simplicity" on a four-point scale. If the item scored more than $75 \%$ in relevance, its "clearness" and "simplicity" were evaluated, as well. The content validity of the whole tool was also calculated. In this context, the Scale CVI/Average (SCVI/Ave) criterion was measured. In order to evaluate the $\mathrm{CVI}$, the modified Cohen kappa was computed as the indicator of agreement among the evaluators. Modified kappa with cut-off points ranging from 0.4 to 0.59 as poor, 0.6 to 0.74 as good, and more than 0.74 as excellent was accepted in this study $(31,32)$.

1-C) Construct validity: In this study, exploratory factor analysis was used to determine the construct validity of the questionnaire. The number of samples required in factor analysis varies from three to ten per item $(33,34)$. Therefore, the study sample consisted of 600 nurses who were randomly selected from all the hospitals affiliated to Shiraz University of Medical Sciences. The inclusion criteria were having A.D., B.Sc., and M.Sc. degrees in nursing and having at least one year of clinical experience. Prior to factor analysis, Kaiser-Meyer-Olkin (KMO) test was performed for sampling adequacy. Moreover, Cronbach's alpha coefficients of the questionnaire and its subscales were calculated by Intra-Cluster Correlation (ICC). Then, the BT correlation matrix of the variables was evaluated. The variables with a correlation coefficient less than $0.3 \%$ were excluded $(35,36)$. In factor analysis, after calculating the correlation matrix, the highly correlated variables were grouped into one category or factor. Afterwards, scree plot values were used to extract the factors of the professional discrimination instrument. The factor load of more than 0.4 was considered in the present study.

2. Reliability: The stability and internal consistency of the questionnaire were assessed in this study. 2-A): Internal consistency: Cronbach's alpha was measured to determine the internal consistency of the questionnaire. Accordingly, scores equal to or greater than 0.7 were considered to be acceptable (35). 
2-B) Stability: Stability refers to achieving the same scores in a group of people in two stages (34). In this study, the stability of the questionnaire was assessed via the test-retest method. In doing so, the questionnaire was distributed among 30 participants and completed for the second time within two weeks. The reliability coefficient was calculated by Pearson's correlation coefficient and ICC. If the ICC index was higher than 0.8 , the stability was favorable. All data analyses were carried out using the SPSS statistical software, version 24 .

Ethical considerations: This study was approved by the Ethics Committee of Shiraz University of Medical Sciences (code: IR.SUMS.REC.1398.988). Informed consent forms were obtained from the study participants. They were informed that the data would be used solely for the benefit of the participants. They were also assured about the anonymity of their data.

\section{Results}

Qualitative phase

According to the definitions of Western and Iranian texts, it could be concluded that professional discrimination contained some similar concepts, such as discrimination in promotion and access to educational opportunities, discrimination in employment improvement and promotion, disparities in welfare compared to other careers such as physicians, disparities in superiors' behaviors towards inferiors like nurses in different situations, sexual and ethnic discrimination, and the consequences of discrimination.

Quantitative phase

After conceptualization of these dimensions and determination of the operational definitions, the questionnaire items with 46 items were extracted. Then, the items were reviewed by the research team in terms of meaning, repetition, and overlapping. Accordingly, 7 items were deleted. Some changes were also made to the wording of the items. For example, pronouns were removed from or added to the beginning of some sentences. The final questionnaire included 42 items divided into 3 main categories and 6 subcategories as follows: dimension 1, interprofessional discrimination including nurse/doctor relationship (6 items) and nurse/other healthcare members (9 items); dimension2, intraprofessional discrimination including gender/ethnic discrimination (10 items), cultural discrimination (3 items), religious discrimination (4 items), and socio-economic discrimination (5 items); and dimension 3 , discrimination outcomes ( 4 items). The items were scored on a five-point Likert scale ranging from "strongly disagree" to "strongly agree" and were prepared for psychometric evaluation.

At this stage, 579 nurses were recruited. The mean age of the participants was 29.63 (6.35) years. Most of the samples were female (85\%), single (49.4\%), and employed $(71.3 \%)$ and had B.Sc. degrees $(90.8 \%)$.

In qualitative face validity, changes were made to the questionnaire based on the participants' comments and 6 items were deleted. Afterwards, all items that had obtained IS more than 1.5. As for the CVR, 
according to the Lawshe table, the scores of 33 items were higher than the table number and 3 items were less. According to the cut-off point of 0.78 for $\mathrm{CVI}, 2$ items of those 3 items did not obtain the minimum score and were omitted. Moreover, the Kappa statistic was "perfect" for the rest of items and, consequently, the items were sustained. S-CVI of the questionnaire was also calculated as 0.904 .

Considering factor analysis, the KMO test showed the adequacy of sampling and BT test was significant $(p<0.001)$ (table1). This indicated that the variables were sufficiently correlated and the conditions were satisfactory for performing factor analysis. Then, Eigenvalues and scree plot (Figure 1 and table 2) were used to extract the questionnaire factors. According to the tables, $53.87 \%$ of the cumulative variance could be explained by the first five factors (Table 3). Factor 1 named as horizontal and vertical discrimination consisted of 14 items (6,14 to 20 and 22 to 27), factor 2 as discrimination's outcome containing 6 items $(28,29,30,31,32,33)$, factor 3 as Inequality due to employment, education and ethnicity, consisting of 4 items $(8,9,10,21)$, factor 4 entitled Unequal job promotion containing 4 questions $(4,5,12,13)$, and factor 5 as gender/cultural discrimination contained 5 items $(1,2,3,7$ and 11).

In this study, the internal consistency of the questionnaire was assessed after determining its face and content validity. To this end, the internal consistency of the pilot questionnaire was assessed in a 600individual sample prior to performing the factor analysis. The Cronbach's alpha coefficients were found to be 0.813 , respectively.

To determine the stability of the instrument, 30 nurses were asked to answer the questionnaire items twice within two weeks. The results showed no significant differences between the scores of the entire questionnaire and its dimensions at the two stages $(p>0.05)$. Therefore, the concept of professional discrimination remained constant at two different times and it could be concluded that the questionnaire was sufficiently stable.

Questionnaire scoring: After constructing the final questionnaire with 33 items in a five-point Likert scale, scores one and five were assigned to 'completely disagree' and 'completely agree', respectively. Besides, inverse scoring was performed for the four items $(4,14,18,19)$ whose semantic loads were reversed. Thus, the questionnaire scores could range from 33 to 165 and higher scores indicate greater discrimination in the workplace.

\section{Discussion}

The present study aimed to design and validate the professional discrimination questionnaire. The results showed that the 33-item questionnaire had appropriate validity and reliability. Moreover, an overview of the existing tools indicated that the present questionnaire performed better than many similar questionnaires both in terms of the specificity of measuring the concept and evaluation of psychometric properties. For example, the EOD questionnaire showed good construct validity across studies. This means that considering the convergent validity, the correlation with Williams Discrimination Questionnaire was higher than 0.55 (37). Indeed, the results of confirmatory factor analysis indicated the one- 
dimensionality of the questionnaire. Additionally, the reliability of the questionnaire was confirmed by $a>0.74$ and $r=0.7$ in the test-retest method. However, there is no report on the face and content validity of the questionnaire $(10,21,38)$. The EDS and MED questionnaires (Williams 1997) also deal with inappropriate behaviors in daily life, including disrespectful behaviors or being exposed to unfair situations such as inappropriate workplace promotion. Factor analysis confirmed the construct validity of these questionnaires in one dimension. Criterion-related validity also showed that perceived racial discrimination in adolescents was positively correlated to extrinsic $(r=0.34 ; p<0.005)$ and intrinsic symptoms $(r=0.39 ; p<0.001)$. Indeed, the alpha coefficient of 0.87 and split-half coefficient of 0.83 indicated the appropriate reliability of the questionnaire $(37,39-41)$. Criterion validity and factor analysis were among the strengths of this questionnaire. However, it is unclear how the face and content validity of the questionnaire were assessed. The PEDQ-CV questionnaire assesses perceived racial discrimination in community and university settings (22). The alpha coefficient of this questionnaire ranged from 0.74 to 0.87 in the long form and from 0.65 to 0.88 in the short form. Concerning convergent validity, studies showed that the short form of the questionnaire correlated to the Perceived Racial Discrimination (PRS) questionnaire in black $(r=0.61 ; p<0.001)$ and Latin $(r=0.57 ; p<0.001)$. Evaluation of discriminant and concurrent validity also showed a correlation between the short form of the questionnaire and threat assessment $(r=0.43 ; p<0.001)$ and harm assessment $(r=0.46 ; p<0.001)$. The correlation between the short form and threat assessment $(r=0.37 ; p<0.001)$ and loss assessment $(r=0.27, p<0.05)$ after controlling for personality measures confirmed the validity of the questionnaire, as well. Nonetheless, failure to perform factor analysis was one of the main limitations of this questionnaire. Yet, the designer of the questionnaire attempted to prove its construct validity to some extent via concurrent validity. Moreover, Cronbach's alpha coefficient was calculated as 0.42 in the organizational justice questionnaire (25). Undoubtedly, the conceptualization of organizational justice differs from that of professional discrimination. Hence, this questionnaire cannot be used for examining professional discrimination.

Overall, the current professional discrimination questionnaire is considered to be valuable in health policymaking as it specifically examines the concept of professional discrimination. Besides, psychometric analysis of the questionnaire increased its accuracy. Cronbach's alpha>0.9 also indicated the internal consistency of the questionnaire compared to the existing instruments. Another strong point of the present study was combining two qualitative and quantitative approaches and providing a deeper insight into the research problem. Hence, the characteristics of professional discrimination, which were described in the qualitative phase, were precisely measured in the present questionnaire. Finally, the existence of reversal items provided another strong point for the questionnaire. On the other hand, one of the most important considerations in this questionnaire is the overlap of the concept of professional discrimination with such concepts as injustice, unfair treatment, and disparity. The closeness of these concepts to each other might have led to misunderstandings at different stages of the study. The researchers' experiences and mentalities might have also influenced the study findings. Therefore, the results of the conceptualization of professional discrimination in this study might not be replicated in similar studies because the reality is not the same from the point of view of naturalistic researchers. Another important point is that because the questionnaire had to be completed by the participants, some 
participants might have reported their perceived discrimination higher or lower than the actual level (11). Thus, researchers are recommended to use other methods, such as observation, to evaluate this phenomenon in addition to using the questionnaire. Furthermore, application of this questionnaire in the field of health requires further studies on its validity and reliability. Hence, confirmatory factor analysis is suggested to be performed among other healthcare teams.

\section{Conclusions}

Measurement of professional discrimination could provide health managers and decision-makers with highly accurate and documented information. This way, health policymakers could identify the factors associated with this challenge to take the necessary measures. Resolving this problem could be also beneficial for health services of these systems' stakeholders.

\section{List Of Abbreviations}

MED: Major Experiences of Discrimination Scale

EDSE: Everyday Discrimination Scale

MED: Major Experiences of Discrimination Scale

CVR: Content Validity Ratio

CVI: Content Validity Index

ICC: Intra-Cluster Correlation

KMO: Kaiser-Meyer-Olkin

I-CVI: Item-Content Validity Index

SCVI/Ave: Scale CVI/Average

PEDQ-CV: Perceived Ethnic Discrimination Questionnaire-Community Version

EODS/EOD: Experience Discrimination Scale

\section{Declarations}

\section{Ethics approval and consent to participate}

Ethics approval was obtained from Shiraz University of Medical Sciences, Iran, Human Research Ethics Committee (16671). Participation was voluntary, and written informed consent was obtained from the participants. 


\section{Consent for publication}

The authors declare no potential conflicts of interest with respect to the research, authorship, and/or publication of this article.

\section{Availability of supporting data}

The datasets used and/or analysed during the current study are available from the corresponding author on reasonable request.

\section{Competing interest}

The authors declare that they have no competing interests.

\section{Funding}

The project was supported by the Vice-Chancellor for Research Affairs of Shiraz University of Medical Sciences, Iran

\section{Authors' contributions}

CT was responsible for the study conception. FZKH collected the data and conducted initial analyses along with AJ and CTZ. All authors were involved in interpretation of the data. AJ conducted the secondary analysis and wrote the first draft. All authors revised it critically for important intellectual content. All authors have read the final commentary, agreed to its content, and are accountable for all aspects of the accuracy and integrity of the manuscript.

\section{Acknowledgements}

This manuscript was extracted from MS thesis written by Fatemeh ZareKhafri and financially supported by the Vice-Chancellor for Research Affairs of Shiraz University of Medical Sciences, Shiraz, Iran (IR.SUMS.REC.1398.988). The authors would like to thank Ms. A. Keivanshekouh at the Research Improvement Center of Shiraz University of Medical Sciences for improving the use of English in the manuscript. Thanks also go to the participants who participated in this study

\section{References}

1. Abbaszadeh A, Borhani F, MoazenNematollahi L. The comparison of the level of moral sensitivity in nursing students and nursing staffs in Kerman in 1389. Medical ethics. 2016;4(12):39-54 [persian].

2. Kaabomeir N, Naami A. The Effect of Perceived Organizational Justice on Organizational Loyalty and Job Well-being With Mediating Role of Social Undermining and Moderating Role of Job Control in Employees of Ahwaz Golestan Hospital. Journal of nursing education. 2016;55(3):55-63 [persian].

3. Association AN. Discrimination and racism in health care. ANA Nursing World. 1998. 
4. Lamont M, Silva GM, Welburn J, Guetzkow J, Mizrachi N, Herzog H, et al. Getting respect: Responding to stigma and discrimination in the United States, Brazil, and Israel: Princeton University Press; 2016.

5. Hershcovis MS, Barling J. Towards a multi-foci approach to workplace aggression: A meta-analytic review of outcomes from different perpetrators. Journal of Organizational Behavior. 2010;31(1):2444.

6. Klinner NS, Walsh G. Customer perceptions of discrimination in service deliveries: Construction and validation of a measurement instrument. Journal of Business Research. 2013;66(5):651-8.

7. Sanders Thompson VL. Coping Responses and the Experience of Discrimination 1. Journal of Applied Social Psychology. 2006;36(5):1198-214.

8. Morgan AJ, Reavley NJ, Jorm AF, Beatson R. Experiences of discrimination and positive treatment from health professionals: A national survey of adults with mental health problems. Australian \& New Zealand Journal of Psychiatry. 2016;50(8):754-62.

9. Seng JS, Lopez WD, Sperlich M, Hamama L, Meldrum CDR. Marginalized identities, discrimination burden, and mental health: Empirical exploration of an interpersonal-level approach to modeling intersectionality. Social Science \& Medicine. 2012;75(12):2437-45.

10. McFarland RL. An analysis of the association between perceived discrimination and self-reported health among university students in Southwest Florida: Florida Gulf Coast University; 2013.

11. Lewis TT, Cogburn CD, Williams DR. Self-reported experiences of discrimination and health: scientific advances, ongoing controversies, and emerging issues. Annual review of clinical psychology. 2015;11:407-40.

12. Schmitt MT, Branscombe NR, Postmes T, Garcia A. The consequences of perceived discrimination for psychological well-being: A meta-analytic review. Psychological bulletin. 2014;140(4):921.

13. Williams DR, Mohammed SA. Discrimination and racial disparities in health: evidence and needed research. Journal of behavioral medicine. 2009;32(1):20-47.

14. Allan HT, Cowie H, Smith P. Overseas nurses' experiences of discrimination: a case of racist bullying? Journal of nursing management. 2009;17(7):898-906.

15. Baraz S, Memarian R, Vanaki Z. Learning challenges of nursing students in clinical environments: A qualitative study in Iran. Journal of education and health promotion. 2015;4.

16. Neiterman E, Bourgeault IL. The shield of professional status: Comparing internationally educated nurses' and international medical graduates' experiences of discrimination. Health:. 2015;19(6):61534.

17. Shohani M. Strategies of Iranian nurses to overcome professional discrimination: An explorative qualitative study. Nursing ethics. 2017:0969733017700233.

18. Valizadeh L, Zamanzadeh V, Irajpour A, Shohani M. " Discrimination", the Main Concern of Iranian Nurses over Inter-Professional Collaboration: an Explorative Qualitative Study. Journal of caring sciences. 2015;4(2):115.

19. Jefferson K. Performance of the Everyday Discrimination Scale: a Three Group Comparison. 
20. Williams DR. Measuring discrimination resource. 2016.

21. Krieger N, Smith K, Naishadham D, Hartman C, Barbeau EM. Experiences of discrimination: validity and reliability of a self-report measure for population health research on racism and health. Social science \& medicine. 2005;61(7):1576-96.

22. Brondolo E, Kelly KP, Coakley V, Gordon T, Thompson S, Levy E, et al. The perceived ethnic discrimination questionnaire: development and preliminary validation of a community version 1 . Journal of Applied Social Psychology. 2005;35(2):335-65.

23. Moorman RH. Relationship between organizational justice and organizational citizenship behaviors: Do fairness perceptions influence employee citizenship? Journal of applied psychology. 1991;76(6):845.

24. Moorman RH, Blakely GL, Niehoff BP. Does perceived organizational support mediate the relationship between procedural justice and organizational citizenship behavior? Academy of Management journal. 1998;41(3):351-7.

25. Moorman RH, Niehoff BP, Organ DW. Treating employees fairly and organizational citizenship behavior: Sorting the effects of job satisfaction, organizational commitment, and procedural justice. Employee responsibilities and rights journal. 1993;6(3):209-25.

26. Doward, LC., Meads, DM., Thorsen, H. Requirements for quality of life instruments in clinical research. Value in health. 2004;7:S13-S6.

27. Fisher J. Development and Application of a Spiritual Well-Being Questionnaire Called SHALOM. Religions. 2010;1:105-21.

28. Meissner, I. H, Creswell, W. J, Klassen, Carroll A, et al. Best Practices for Mixed Methods Research in the Health Sciences: Office of Behavioral and Social Sciences Research (OBSSR); 2014 [cited 2014].

29. Waltz, CF., Strickland, Ol., Lenz, ER. Measurement in Nursing and Health Research.: Springer Publishing Company; 2010.

30. Lawshe C. A quantitative approach to content validity. Personnel psychology. 1975;28:563-75.

31. Cicchetti, D.V., Sparrow, S. Developing criteria for establishing interrater reliability of specific items: Application to assessment of adaptive behavior. American Journal of Mental Deficiency. 1981;86:127-37.

32. Cicchetti DV. Guidelines, criteria, and rules of thumb for evaluating normed and standardized assessment instruments in psychology. Psychological assessment. 1994;6(4):284.

33. Clark P, V., Creswell, J. Designing and conducting mixed methods research. Thousand Oaks (California): Sage Publications; 2011.

34. LoBiondo-Wood G, Haber J. Nursing research: Methods and critical appraisal for evidence-based practice. St. Louis: Mosby; 2010.

35. Plichta SB, Kelvin EA, Munro BH. Munro s statistical methods for health care research. Philadelphia: Wolters Kluwer Health/Lippincott Williams \& Wilkins; 2013. 
36. Polit, DF., Beck, CT. Essentials of nursing research: Appraising Evidence for Nursing Practice. Philadelphia: Lippincott williams \& wilkins; 2013.

37. Williams DR, Yu Y, Jackson JS, Anderson NB. Racial differences in physical and mental health: Socioeconomic status, stress and discrimination. Journal of health psychology. 1997;2(3):335-51.

38. Cardarelli R, Cardarelli KM, Fulda KG, Espinoza A, Cage C, Vishwanatha J, et al. Self-reported racial discrimination, response to unfair treatment, and coronary calcification in asymptomatic adults-the North Texas Healthy Heart study. BMC public health. 2010;10(1):285.

39. Williams JD, Henderson GR, Harris A-M. Consumer racial profiling: Bigotry goes to market. The New Crisis. 2001;108(6):22-4.

40. Clark R, Coleman AP, Novak JD. Brief report: Initial psychometric properties of the everyday discrimination scale in black adolescents. Journal of adolescence. 2004;27(3):363-8.

41. Sternthal MJ, Slopen N, Williams DR. Racial disparities in health: how much does stress really matter? Du Bois Review: Social Science Research on Race. 2011;8(1):9

\section{Tables}


Table1: the results of KMO and BT

\section{KMO and Bartlett's Test}

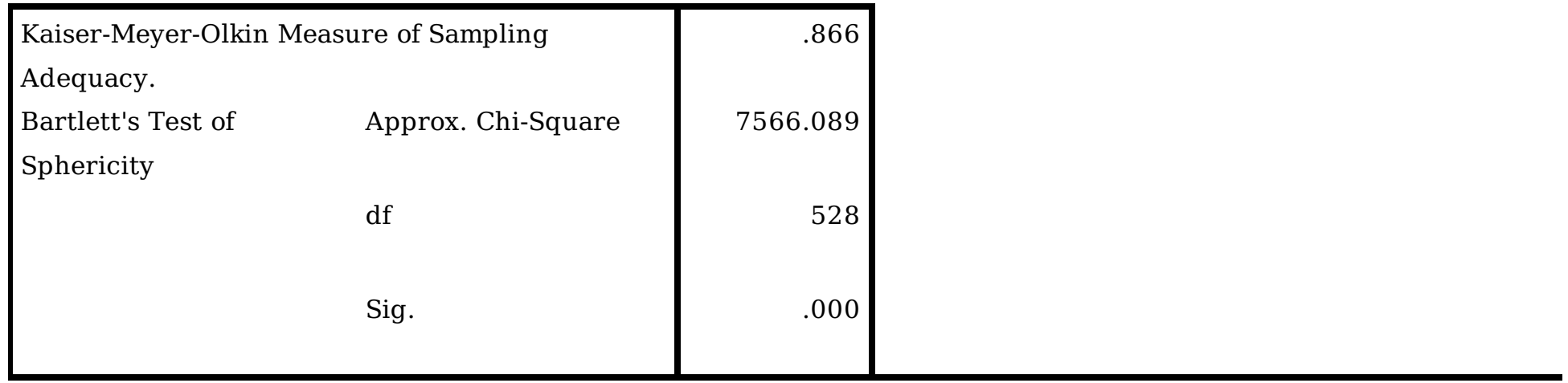

Table2: the results of variance explained by factors

Total Variance Explained

\begin{tabular}{|c|c|c|c|c|c|c|c|c|c|}
\hline \multirow[t]{2}{*}{ Component } & \multicolumn{3}{|c|}{ Initial Eigenvalues } & \multicolumn{3}{|c|}{$\begin{array}{c}\text { Extraction Sums of Squared } \\
\text { Loadings }\end{array}$} & \multicolumn{3}{|c|}{$\begin{array}{c}\text { Rotation Sums of Squared } \\
\text { Loadings }\end{array}$} \\
\hline & Total & $\begin{array}{c}\% \text { of } \\
\text { Variance }\end{array}$ & $\begin{array}{c}\text { Cumulative } \\
\%\end{array}$ & Total & $\%$ of Variance & $\begin{array}{c}\text { Cumulative } \\
\%\end{array}$ & Total & $\begin{array}{c}\% \text { of } \\
\text { Variance }\end{array}$ & $\begin{array}{c}\text { Cumulative } \\
\%\end{array}$ \\
\hline 1 & 9.294 & 28.164 & 28.164 & 9.294 & 28.164 & 28.164 & 8.030 & 24.335 & 24.335 \\
\hline 2 & 3.022 & 9.158 & 37.322 & 3.022 & 9.158 & 37.322 & 2.642 & 8.005 & 32.340 \\
\hline 3 & 2.166 & 6.563 & 43.885 & 2.166 & 6.563 & 43.885 & 2.567 & 7.778 & 40.118 \\
\hline 4 & 1.850 & 5.607 & 49.492 & 1.850 & 5.607 & 49.492 & 2.561 & 7.761 & 47.879 \\
\hline 5 & 1.444 & 4.376 & 53.868 & 1.444 & 4.376 & 53.868 & 1.976 & 5.989 & 53.868 \\
\hline 6 & 1.370 & 4.150 & 58.018 & & & & & & \\
\hline 7 & 1.179 & 3.574 & 61.592 & & & & & & \\
\hline 8 & 1.051 & 3.184 & 64.776 & & & & & & \\
\hline 9 & .977 & 2.962 & 67.737 & & & & & & \\
\hline 10 & .894 & 2.709 & 70.446 & & & & & & \\
\hline 11 & .837 & 2.537 & 72.983 & & & & & & \\
\hline 12 & .738 & 2.237 & 75.220 & & & & & & \\
\hline 13 & .702 & 2.126 & 77.346 & & & & & & \\
\hline 14 & .655 & 1.985 & 79.330 & & & & & & \\
\hline 15 & .615 & 1.865 & 81.195 & & & & & & \\
\hline 16 & .585 & 1.773 & 82.968 & & & & & & \\
\hline 17 & .548 & 1.661 & 84.629 & & & & & & \\
\hline
\end{tabular}




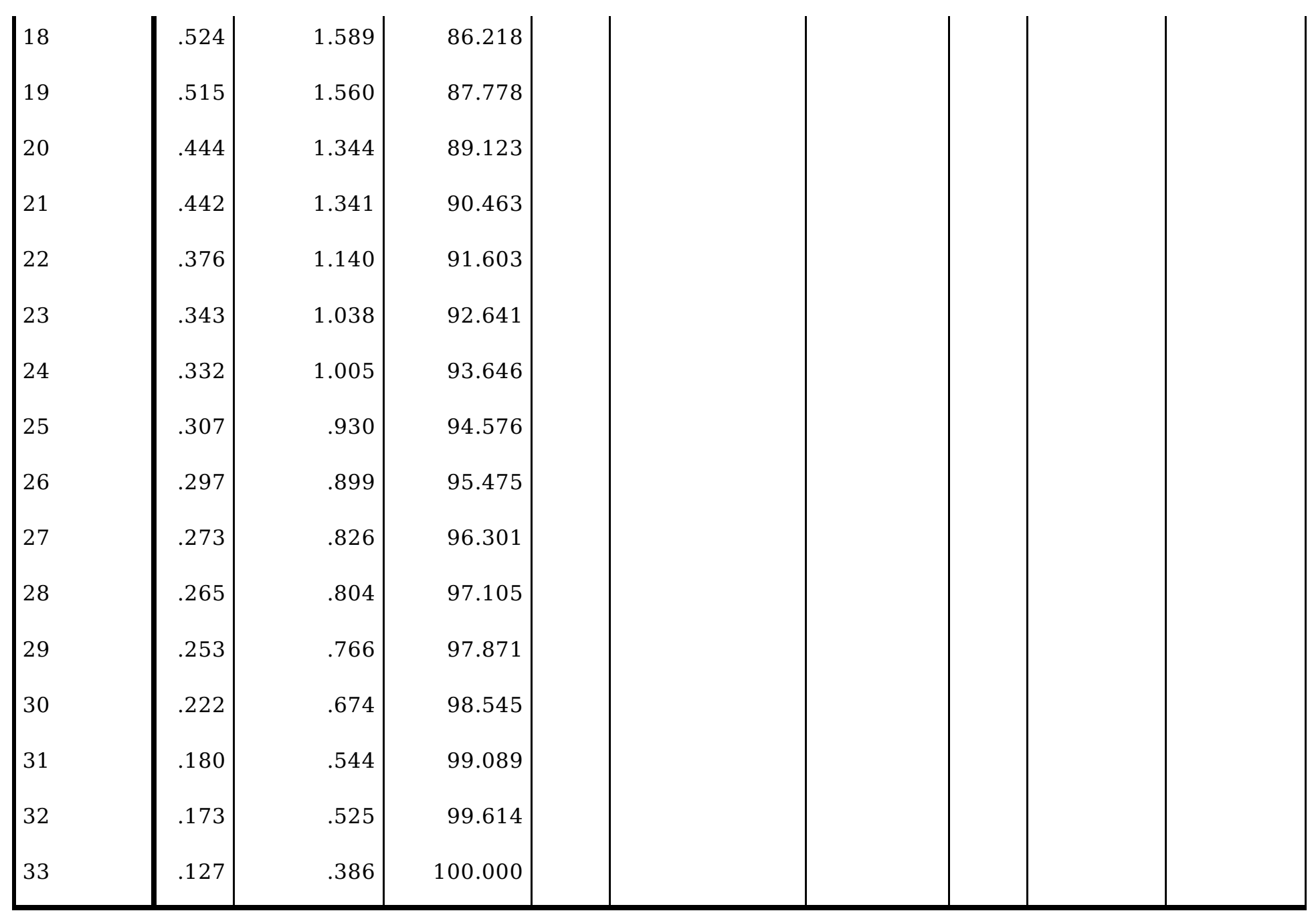

Extraction Method: Principal Component Analysis. 
Table 3: factor loadings of the items

Component Matrix ${ }^{\mathrm{a}}$

\begin{tabular}{|c|c|c|c|c|c|}
\hline & \multicolumn{5}{|c|}{ Component } \\
\hline & 1 & 2 & 3 & 4 & 5 \\
\hline q1 & & .432 & & & \\
\hline q2 & & .715 & & & \\
\hline q3 & .572 & & & & \\
\hline q4 & -.585 & & & & \\
\hline q5 & & .409 & .432 & & \\
\hline q6 & .570 & & & & \\
\hline q7 & & .437 & .656 & & \\
\hline q8 & & .411 & & -.572 & \\
\hline q9 & & .555 & & & \\
\hline q10 & & .459 & -.411 & & \\
\hline q11 & .427 & & & & \\
\hline q12 & .418 & & & -.418 & \\
\hline q13 & & & & & .476 \\
\hline q14 & -.614 & & & & \\
\hline q15 & .701 & & & & \\
\hline q16 & .747 & & & & \\
\hline q17 & .612 & & & & \\
\hline q18 & -.673 & & & & \\
\hline q19 & -.535 & & & .453 & \\
\hline q20 & & & & & .454 \\
\hline q21 & & & -.691 & & \\
\hline q22 & .673 & & & & \\
\hline q23 & & & & & .462 \\
\hline q24 & .700 & & & & \\
\hline q25 & .689 & & & & \\
\hline q26 & .738 & & & & \\
\hline q27 & .700 & & & & \\
\hline q28 & .769 & & & & \\
\hline q29 & & .458 & & & \\
\hline q30 & .782 & & & & \\
\hline q31 & .741 & & & & \\
\hline q32 & .648 & & & & \\
\hline q33 & .447 & & & & \\
\hline
\end{tabular}

Extraction Method: Principal Component Analysis.

a. 5 components extracted. 


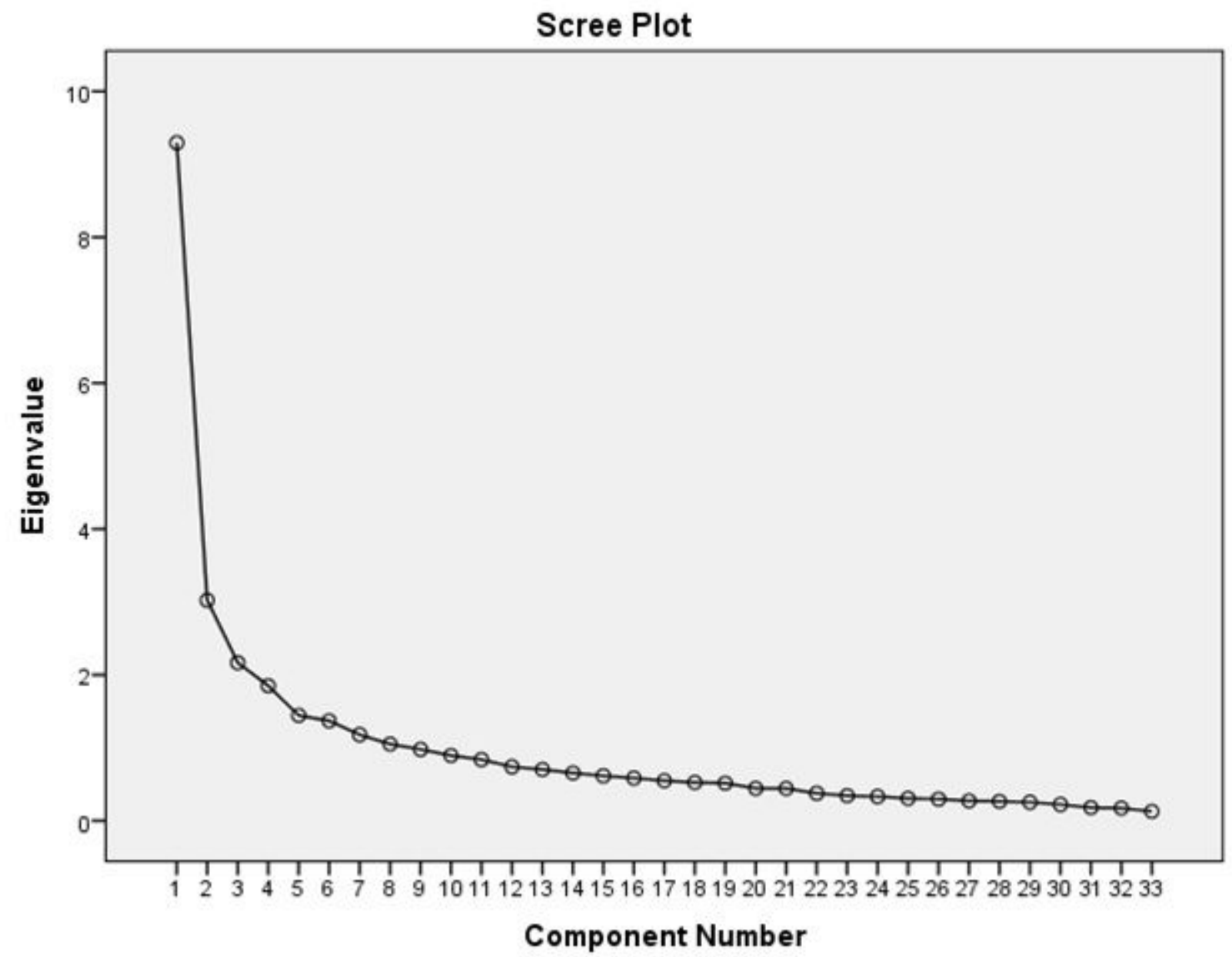

Figure 1

the Scree plot of the factors 